\title{
Condições para o desenvolvimento da agricultura familiar no capitalismo contemporâneo
}

\section{Conditions to the development of the familiar agriculture in the current capitalism}

\author{
Celestino de Oliveira Brito ${ }^{1}$
}

\section{Resumo}

As primeiras análises acerca do desenvolvimento do capitalismo na agricultura apontavam que uma modernização presidida pela lógica da indústria urbana inviabilizaria a atividade em pequenas unidades de produção. Análises contemporâneas têm corroborado essa tese. Aquelas pequenas unidades de produção que mergulharam a fundo na modernização das suas bases técnicas, com produção voltada exclusivamente para o mercado, não têm obtido retornos econômicos satisfatórios para amortizar suas dívidas, pois estão constantemente em crise e dependem da política estatal. Contrariamente, aquelas unidades familiares nas quais os agricultores têm sabido equilibrar o conhecimento tradicional com o moderno, e aliam a produção para o autoconsumo à produção para o mercado, têm tido maior capacidade para sobreviver às crises que costumeiramente se abatem sobre o mercado.

Palavras-chave: Capitalismo. Agricultura familiar. Estado. Mercado.

\begin{abstract}
First analyses of the development of agriculture capitalism have indicated that modernization presided by the logic of urban industry would make this activity in small production units impossible. Contemporary analyses have confirmed this thesis. These small units of production that have invested strongly in modernizing their technical basis, and targeted their production exclusively to the market, have not had any satisfactory economic returns to reduce their debts, being constantly in crisis and dependent on state politics. On the other hand, those familiar units, where farmers have learned how to balance traditional with modern knowledge and to connect production for self-consumption to market production, have developed greater capacity for surviving the crisis that usually hit the market.
\end{abstract}

Key words: Capitalism. Family agriculture. State. Market.

1 Mestre em Sociologia pela UFPR - Área de concentração trabalho e ruralidades. E-mail: celestinobrito@ibest.com.br 


\section{Introdução}

O capitalismo industrial é entendido como a vertente da razão moderna que institucionalizou a técnica e a ciência como instrumentos propulsores de seu desenvolvimento. Na sociedade capitalistaindustrial, desenvolver-se significa aumentar a capacidade de domínio sobre a natureza. Em decorrência dessa condição fundante, as empresas, para desenvolverem-se neste sistema, precisam modernizar-se constantemente. A eficiência da empresa está condicionada à sua capacidade em poder compatibilizar suas atividades produtivas aos imperativos da ciência e da técnica, tendo em vista o aumento da produção. De acordo com Marx (1980), o capitalismo, à medida que se instala na agricultura, subordina-a ao capital; transforma a agricultura, que deixa os processos da fração menos evoluída da sociedade, puramente empíricos e prisioneiros da tradição, forçando-a a aplicar, de maneira consciente e científica, a agronomia. Vem daí a tese que apontava para o definhamento da pequena unidade de produção agrícola. A justificativa é que a pequena unidade de produção, por si só, não reúne condições para implementar as inovações técnicocientíficas impostas como modernizantes. Segundo Kautsky (1986) esse fato tenderia a ocorrer, caso a regulamentação do processo produtivo fosse dirigida exclusivamente pelas regras do mercado.

Muitos autores contemporâneos, principalmente técnicos e gestores de política pública para o setor agrícola, têm se apressado em demonstrar as vantagens auferidas pela sociedade em decorrência do triunfo da racionalidade técnicocientífica, dita moderna, sobre as formas de produção tradicionais ou não-capitalistas. Em função do seu comprometimento com aquela visão de desenvolvimento, ignoram, e até mesmo tentam desqualificar, qualquer outra percepção que venha a advertir ou mesmo apontar a existência de limites para a adoção das tecnologias e das máquinas modernizadoras pelas pequenas unidades de produção. Para legitimarem seu ponto de vista, argumentam que as pequenas unidades de produção agrícola estão presentes no mundo inteiro e apresentamumacondição bastantemodernizada. Não demonstram, porém, quais elementos e (ou) fatores têm possibilitado com que esses estabelecimentos adotem avanços técnico-científicos, bem como as condições em que se tem dado essa evolução ao longo do processo de desenvolvimento do sistema ou modo de produção capitalista. Como conseqüência dessa análise comprometida, têm-se duas modalidades equivocadas de interpretação: a recusa em enxergar a política de concessão de subsídios à produção agrícola como uma condição necessária para que ela possa se modernizar; e a tentativa de ignorar toda e qualquer contribuição que possa ser oferecida pelo conhecimento dito tradicional.

$\mathrm{O}$ texto se propõe a examinar as reais possibilidades de desenvolvimento para a agricultura familiar no capitalismo contemporâneo. Recorrendo aos estudos da fase de capitalismo liberal, procura identificar quais seriam as chances de reprodução socioeconômica dessa forma de produção, em um cenário em que as decisões sobre a produção fossem dirigidas exclusivamente pelas regras do mercado. Com base em estudos contemporâneos realizados em alguns países europeus, busca entender como esse desenvolvimento está se dando no cenário atual, em países de capitalismo avançado. Também, apoiado em estudos de autores brasileiros consagrados, busca demonstrar as condições de desenvolvimento da agricultura familiar no Brasil.

\section{O Desenvolvimento do Capitalismo Liberal na Agricultura: Conseqüências para as Pequenas Unidades de Produção}

Conforme relata Kautsky (1986), na sua obra “모 Questão Agrária” - editado em 1898 e traduzido no Brasil em 1986 -, o modo de produção capitalista se desenvolve, via de regra, primeiramente nas cidades, e na indústria, em primeiro lugar. A agricultura permanece intocada por muito tempo e longe da influência da cidade. Até então, o camponês era um misto de agricultor e artesão. 
A família camponesa constituía uma cooperativa completamente ou quase totalmente auto-suficiente que não só produzia seus próprios produtos de consumo pessoal; construía também a própria casa; fabricava os próprios móveis e utensílios domésticos, inclusive a maioria das ferramentas toscas de que necessitava; curtia o couro, preparava o linho e a lã, fazia as próprias roupas. O camponês ia ao mercado, mas lá vendia tão somente os excedentes de sua produção, comprando o indispensável, com exceção do ferro do qual só utilizava o mínimo necessário. Desse mercado poderia depender o luxo, jamais a própria existência. Mesmo uma má colheita representava um mal passageiro. Contra a má colheita protegiam-nos as grandes provisões que haviam armazenado; o gado fornecia o leite e a carne; a floresta e os mananciais também contribuíam para a sua mesa (KAUTSKY, 1986).

Conforme podemos observar no comentário de Sismondi, citado a seguir, a organização familiar do trabalho e a produção para o autoconsumo são dois pilares da pequena unidade de produção agrícola que lhes concedem independência em relação aos condicionantes externos.

O lavrador que, com a ajuda de seus filhos, dá conta do serviço em sua pequena propriedade; esse homem que não paga nenhuma taxa de arrendamento a ninguém acima dele; que não paga ordenado a ninguém abaixo dele; que organiza sua produção de acordo com as necessidades de seu próprio consumo; que come o próprio trigo e bebe o próprio vinho; que veste a roupa com linho que ele mesmo cultiva, ou com a lã da sua própria criação; esse é o agricultor que pouco se importa com os preços do mercado, pois pouca coisa tem a comprar ou vender, não sendo por isso nunca arruinado pelas crises que afetam o comércio (SISMONDI apud: KAUTSKY, 1986).

É só como conseqüência do desenvolvimento industrial que o modo de produção capitalista vai modificar o caráter da produção agrícola. $\mathrm{O}$ advento da indústria capitalista vem abalar o outro pilar que completava o tripé de sustentação da pequena unidade de produção agrícola: a indústria artesanal de consumo e subsistência.

O desenvolvimento da indústria e do comércio gerou a demanda de novos produtos na cidade, demanda que a indústria agrícola era incapaz de satisfazer; esses produtos, a exemplo das ferramentas novas e mais perfeitas, também começaram a invadir o campo em ritmo crescente na medida em que aumentava o intercâmbio entre cidade e campo. As túnicas e as peles de animais foram substituídas por roupas de pano, os sapatos de palha por botas de couro e assim por diante (KAUTSKY, 1986).

A evolução industrial passa a determinar cada vez mais a lei da evolução agrícola, forçando-a a adotar o emprego sistemático de máquinas e novas tecnologias.

Com a dissolução da indústria artesanal de consumo e subsistência, o camponês passa a dedicar-se exclusivamente à agricultura; transforma-se em um simples agricultor. "E quanto mais ele se transformava em agricultor, ou quanto mais se completava a separação entre a indústria e a agricultura, mais depressa desaparecia aquela auto-suficiência, segurança e conforto da existência camponesa observadas por Sismondi" (KAUTSKY, 1986, p. 19).

A imposição da especialização produtiva faz com que os agricultores deixem de produzir até mesmo a maior parte dos alimentos que consomem e passam a adquiri-los das empresas especializadas. Também, são as empresas especializadas que se dedicam à produção e à melhoria de sementes, ao desenvolvimento de raças especiais de animais. Com isso, cresce a demanda de dinheiro entre os agricultores. Eles agora não só necessitam de dinheiro para obter o dispensável ou supérfluo, mas dele necessitam igualmente para o necessário, o indispensável.

À medida que o agricultor tem que converter seus produtos em dinheiro, levando-os para vendê-los, 
ele passa a depender do mercado que a ele se revela mais caprichoso e imprevisível que o tempo. Onde ele não tem meios de evitar a baixa dos preços, nem tornar vendável o produto encalhado. Onde a benção da boa colheita pode se transformar uma desgraça. Assim como as más colheitas elevam os preços, as boas colheitas fazem-nos baixar (KAUTSKY, 1986, p. 19-20).

Kautsky adverte que "transformar a agricultura em atividade mais moderna, que participe ininterruptamente do processo técnico e econômico em andamento exige dinheiro - muito dinheiro. Sem dinheiro ou, melhor dizendo, sem capital é impossível haver qualquer atividade agrícola moderna" (KAUTSKY, 1986, p. 57). Isso, segundo Lênin (1982), vai depender de créditos e, conseqüentemente, de garantias que habilitem o agricultor a obter crédito.

Duas modalidades de crédito serão necessárias: o crédito hipotecário como forma de obter capital fixo para melhoramentos, tais como, máquinas, equipamentos e construções; e, capital pessoal para comprar insumos, sementes, defensivos, herbicidas e adubos. Para o grande proprietário agrícola, no curso da evolução capitalista, o empréstimo usurário toma a forma de crédito moderno de produção, cuja taxa se adapta à taxa de lucro. Quanto ao pequeno proprietário, é obrigado a recorrer ao prestamista vampiro, que suga o que pode sugar, cobra juros em desproporção com a taxa de lucro, e assim, em lugar de ajudar a produção, solapa inteiramente a existência do devedor (LÊNIN, 1982).

Lênin lembra, ainda, que os investimentos com máquinas só podem ser amortizados sob um imenso volume de produção, o que as torna acessíveis apenas aos grandes proprietários.

Precisamos considerar que são análises realizadas em uma época de capitalismo liberal, em um cenário de concorrência perfeita, no qual, segundo Ellis (apud ABRAMOVAY, 1998, p. 117), "não há nenhuma forma de interferência externa ao processo, onde há liberdade de entrada e saída em qualquer ramo da atividade, a competição assegura que os produtores ineficientes sejam eliminados da produção e só os mais eficientes sobrevivam".

Kautsky (1986, p. 12) observa que "não se tratava de dogma marxista, era igualmente a concepção da economia burguesa, e a opinião estava em harmonia com os fatos observados na Inglaterra, na Alemanha, na França e na Bélgica naquele momento".

Mas, mesmo em meio a todas essas evidências, Kautsky (1986, p. 15) faz uma observação importante, "a agricultura não se desenvolve, em absoluto, como cópia fiel da indústria, mas de acordo com suas próprias leis". Por isso, aconselhanos a não proferir uma sentença final sobre os destinos da produção agrícola, sem antes examinar o sentido que as transformações adquirem ao serem aplicadas à produção agrícola, nas várias fases do desenvolvimento.

Kautsky (1986, p. 127) chama a atenção, ainda, para "a possibilidade de o Estado poder passar a amparar, por razões políticas, determinados estratos sociais que perderam a sua estabilidade econômica e não conseguem impor-se na produção". Para Kautsky, as próprias formas democráticas dos Estados modernos podem ser entendidas como fatores de sustentação da pequena produção. Quanto mais a luta de classes se agrava, e quanto mais ameaçadora tornar-se a social-democracia, tanto mais os governos estarão propensos a permitir que, às custas da sociedade, através de créditos baratos, seguros baratos etc., os pequenos estabelecimentos supérfluos levem em frente uma existência mais ou menos parasitária. [...] Seu processo de desaparecimento talvez possa ser desacelerado, e é pelo menos essa a esperança que nasce das promessas e medidas governamentais, o que leva muitos a prosseguir em sua luta, luta que teriam abandonado normalmente há muito tempo (KAUTSKY, 1986).

Kautsky (1986) destaca, também, o inacreditável poder de sobrevivência dessas pequenas unidades de produção. Mesmo à custa da fome e do excesso 
de trabalho conseguem prolongar ao máximo a luta que travam por sua existência.

Portanto, a capacidade de superação das adversidades e a interferência da política estatal poderiam vir a converter-se nos potenciais aliados dos pequenos agricultores no sentido de mudar a sina que lhes estava sendo imposta pela sociedade capitalista-industrial.

\section{Do Capitalismo Liberal, Regulado pelo Mercado, ao Capitalismo Regulado pelo Estado: a Democracia, a Esfera Pública e a Reprodução da Agricultura Familiar}

Conforme identificaram Jürgen Habermas (1983) e Offe (1984), acumulação e legitimação são pré-requisitos funcionais para a reprodução do capitalismo. A acumulação continuada é a primeira condição necessária, o requerimento funcional central para a reprodução do capitalismo. A Legitimidade é a segunda condição necessária, porque o consentimento é imprescindível para desarmar a onipresente ameaça revolucionária.

Por várias razões, as condições para que a acumulação possa ocorrer sem interrupção e a legitimação se dê sem conflitos, não são geradas espontaneamente pela economia capitalista.

A competição entre as firmas é incapaz de assegurar que todas as atividades necessárias para a reprodução capitalista continuada sejam espontaneamente realizadas; a economia capitalista não fornece bens públicos suficientes e sua escala se elevou acima das capacidades de provisão privada; as condições não-econômicas necessárias para a continuada produção e troca, como educação, padrões familiares, motivações, não são espontaneamente geradas. (PRZEWORSKY, 1995, p. 90). A não satisfação desses requisitos indispensáveis compromete o desenvolvimento da sociedade capitalista, e coloca em xeque a aposta em uma economia de mercado concorrencial, por conduzi-la na direção da centralização das atividades econômicas.

A difusão de estruturas de mercado oligopolistas e monopolistas modificou as bases do desenvolvimento do capitalismo competitivo. $\mathrm{O}$ mercado desenvolveu "hiatos funcionais" e perdeu a capacidade de dirigir a economia. Então o Estado foi entrando e, por meio do planejamento global, substituiu o mercado no papel de regulador dos conflitos. Os recursos passaram a ser alocados por decisões administrativas. Uma vez que a ideologia da troca justa desmoronou, o sistema não pode mais ser legitimado a partir das relações de troca. Por isso surge, no lugar da ideologia da troca justa, um programa de substitutivos, que não é mais orientado pelas conseqüências sociais da instituição do mercado, mas pelas conseqüências sociais de uma atividade de Estado que compensa as disfunções da troca livre (HABERMAS, 1975, p. 319).

Por fim, o capitalismo liberal ou concorrencial, tão bem analisado por Marx e outros estudiosos de seu tempo, cedeu o lugar a uma nova forma de capitalismo, agora regulado e legitimado pelo Estado.

A função de estruturação da sociedade passa a ser preenchida pela política estatal.

À medida que a solução das disfunções do sistema é transferida para a esfera do Estado, abre-se espaço para a constituição de uma esfera pública. [...] Uma vez que os conflitos gerados na produção são transferidos para a esfera pública, cria-se um ambiente propício para a consolidação da democracia A consolidação da democracia, por sua vez, trouxe à realidade a existência dos sujeitos políticos e a prevalência de seus interesses sobre a pura lógica do mercado (HABERMAS, 1989, p. 22).

De acordo com Francisco de Oliveira (1988), o surgimento simultâneo da democracia e da esfera pública vem negar os automatismos do mercado. 
A estruturação de uma esfera pública confundese com a plenitude da democracia representativa nas sociedades desenvolvidas. Ele mapeia todas as áreas conflitivas da reprodução social. Esse mapeamento decorre do imbricamento do fundo público na reprodução social em todos os sentidos. Não é mais a valorização do valor per se: é a necessidade da reprodução do capital em setores que, por sua própria lógica, talvez não tivessem capacidade de reproduzir-se. Tanto a esfera pública como seu corolário, a democracia representativa, afirmam as classes sociais como expressões coletivas e sujeitos da história. (OLIVEIRA, 1988).

Segundo Offe (1984), a dinâmica do desenvolvimento capitalista apresenta uma tendência permanente à paralisação da viabilidade de mercado dos valores, ou seja, à interrupção das relações de troca. Certas condições precisam ser satisfeitas para que o capitalismo se reproduza, e essas condições não são criadas espontaneamente pelo sistema capitalista de produção e troca. Cabe ao Estado prover tais condições ao desempenhar certas funções, tais como: oferecer aos empresários pessoas preparadas para o trabalho, dar-lhes proteção e cuidar da saúde desses trabalhadores, além de assumir o ônus de pagar aposentadorias e auxílio doença àqueles que não estão mais aptos ao trabalho.

A acumulação é o ponto de referência, mas, conforme Offe (1980), ela ocorrerá apenas: se o investimento privado for lucrativo; se a competição for suficientemente vigorosa para assegurar que a taxa de lucro seja positiva em todos os setores; e se os investimentos que são muito elevados ou pouco lucrativos para as firmas particulares - mas necessários para o conjunto delas - forem realizados pelo Estado.

Esses requisitos confirmam as suspeitas levantadas por Kautsky (1986). O Estado, por razões políticas, passou não só a amparar os estratos sociais que perderam a capacidade econômica de manter-se na relação de troca, mas também assume o papel de reorganizar as relações de troca nos mercados, por meio de políticas que objetivam preservá-la e generalizá-la.

Adescrição das diversas formas de financiamento para a acumulação de capital inclui desde os recursos para a ciência e tecnologia. Passa pelos diversos subsídios para a produção, sustentando a competição das exportações. Vai através dos juros subsidiados para os setores de ponta. Sustenta a agricultura e o mercado financeiro e de capitais através de bancos e/ou fundos estatais, pela utilização de ações de empresas estatais. Intervém na circulação monetária de excedentes, mantém a valorização dos capitais pela via da dívida pública (OLIVEIRA, 1988).

Conforme esclarece Offe (1984), os detentores do poder estatal não fazem isso por decisão espontânea. Em condições democráticas eles provavelmente agiriam na busca de apoio político para conquistar a auto-suficiência, e não teriam interesse pela acumulação. Mas, à medida que o Estado assume o compromisso de implementar medidas para compensar aqueles indivíduos que perdem no jogo econômico, e precisa retirar os recursos materiais de que necessita por meio de mecanismos do sistema tributário, passa a depender do volume de acumulação privada. Por isso, persegue os objetivos de pôr bens infra-estruturais à disposição do processo de produção privado, de forma permanente e com baixos custos, bens infraestruturais. Portanto, é para assegurar sua própria capacidade de funcionamento que os detentores do poder do Estado definem como seu mandamento mais alto o imperativo da constituição e consolidação de um desenvolvimento econômico favorável. E também por isso a atividade do Estado é dirigida para a estabilidade e o crescimento econômico. Acredita-se que o crescimento da economia privada expande automaticamente a base tributária. Esperase que parte dos lucros privados retorne aos cofres públicos na forma de impostos e contribuições para que o Estado possa realizar políticas sociais. 
A ciência e a tecnologia continuam a ser instrumentalizadas a serviço do capital. Por isso, a modernização dos instrumentos utilizados no processo produtivo, como os equipamentos, as máquinas e a obrigatoriedade da utilização de insumos industrializados, continua a sercolocada como condição primordial para a obtenção de incentivos e recursos na forma de créditos para a produção. Dessa forma, o capital financeiro é ou continua a ser transferido por meio do crédito que é concedido aos agricultores para adquirirem insumos, máquinas e equipamentos, para a indústria, garantindo também a acumulação do sistema financeiro. A dependência que, de início, o agricultor familiar mantinha com o comerciante usurário, do crédito pessoal (dependência local)e, em seguida, do setor bancário hipotecário (dependência regional), é rompida com a interferência do Estado por meio da extensão da política pública. Esse fato não elimina a dependência externa do agricultor, apenas a transfere do âmbito local e regional para o âmbito nacional. O agricultor passa a depender da política agrícola desenvolvida pelo Estado, mais ou menos favorável, de conformidade com a capacidade política de influenciar nas decisões dos governos de cada época.

A interferência do Estado, por meio da política agrícola, tem se convertido na condição básica para que possa ser viabilizada a modernização da produção agrícola nas unidades de base familiar. Essa é a opinião compartilhada pelas diversas teorias que tentam explicar a reprodução ou permanência dessa atividade produtiva em sociedades de capitalismo avançado. "Sem ser uma pura criatura do Estado, existe, porém, graças a um conjunto de dispositivos legais e regulamentares, dos quais o Estado é o responsável: das políticas fundiárias de acesso à terra, das políticas de crédito para a modernização ou de diversas disposições jurídicas ou regulamentares" (LAMARCHE, 1998, p. 272).

\section{Condições para a Viabilização da Modernização da Produção Agrícola}

A produção agrícola não pode ser regulada por critérios puramente econômicos, pela racionalidade do mercado. Pelas regras do mercado, a previsão de lucro é estabelecida pela relação entre oferta e demanda: oferta menor que a demanda representa maior lucro. Essa regra pode ser normal para a produção de mercadorias supérfluas como de automóveis, por exemplo, pois aqueles que não têm poder para adquiri-lo continuam a viver sem eles. Acontece que a agricultura produz alimentos, e alimento, apesar de ter sido transformado em mercadoria, é artigo indispensável à reprodução da vida, e, por isso, necessita de outros critérios definidores que permitam que haja um equilíbrio entre a oferta e a demanda, e também é necessário haver algum estoque de reserva. Sabemos, porém, que uma atividade produtiva com tal equilíbrio não se sustenta por si só em uma economia de mercado. Alguém ou alguma organização precisa intervir no processo, complementando as expectativas de lucro estimadas pelos produtores agrícolas, assegurando a sua reprodução social, para o bem da própria sociedade.

É de amplo conhecimento que o custo final dos alimentos influi no comportamento dos salários dos trabalhadores urbanos. Se os preços dos alimentos ficassem a critério exclusivamente do mercado, da oferta e da demanda, certamente precisaria ocorrer uma oscilação constante dos salários, uma vez que os trabalhadores consomem a maior parte do seu salário comprando alimentos para as suas famílias.

Uma política agrária que permitisse a fixação dos preços de produtos agrícolas e pecuários em função dos custos reais da produção, fixados a partir de uma taxa 'satisfatória' de remuneração do capital, implicaria uma elevação dos custos da produção industrial, pois seriam necessários melhores salários para atender às necessidades mínimas de reprodução da mão-de-obra. (MARTINS, 1975, p. 24). 
Em decorrência disso, as despesas com a produção de alimentos precisa ser socializada por toda a sociedade que, de forma indireta, contribui para isso, mediante os subsídios concedidos aos agricultores pelo fundo estatal. Com isso, os alimentos chegam mais baratos à mesa dos trabalhadores urbanos possibilitando uma estabilização dos salários. É por isso que o investimento que o Estado capitalista faz na agricultura se justifica pelas funções globais que preenche para a reprodução do processo de acumulação.

Conforme estudos que foram sintetizados em trabalhos organizados por Abramovay (1998) e Lamarche (1993, 1998), nos países economicamente desenvolvidos, principalmente, na Alemanha, França, Canadá eEstados Unidos, já houve a tentativa de deixar que a produção agrícola fosse orientada exclusivamente pelos mecanismos do mercado. A partir da década de 1950, os governos desses países passaram a direcionar sua política agrícola por um modelo denominado produtivista. Em conformidade com essa opção, os objetivos da política estatal passaram a ser a transformação dos estabelecimentos tradicionais em unidades de produção eficientes e competitivas no mercado. Tendo por base a visão empresarial aplicada a uma empresa capitalistaindustrial, tais países acreditavam que poderiam atingir esse objetivo simplesmente com a adoção de políticas de sustentação de preços e de ajudas proporcionais ao volume de produção.

Em menos de 30 anos, o modelo produtivista atingiu seus limites e o setor passou a sofrer os problemas ligados justamente à modernização acelerada e em larga escala: superprodução; armazenamento de excedentes; danos ambientais provocados tanto pelo emprego de fertilizantes e agrotóxicos quanto pelos próprios sistemas monocultores ligados ao padrão de progresso técnico vigente. A conseqüência foi o endividamento daqueles agricultores familiares que mergulharam a fundo na transformação permanente de suas bases técnicas, nem sempre conseguindo obter o retorno suficiente para amortizar suas dívidas.
A situação de falência em que se encontrava o setor agrícola forçou aqueles governantes a reverem sua política agrícola. A solução encontrada foi abandonar a política de sustentação de preços e de ajudas proporcionais ao volume de produção para substituí-la por uma política de sustentação aos pequenos agricultores, além da redução da produção, para permitir a reprodução de um máximo de estabelecimentos. Uma lógica de produção completamente diferente, produzir menos, mais barato, poluindo menos e nela os aspectos sociais têm preferência sobre os aspectos produtivos. O nível de produção não responde apenas à sinalização que os produtores recebem do mercado e seus mecanismos de preço, sua resposta passa por uma esfera pública, institucional, negociada, que distribui cotas, fixa rendas, estabelece requisitos técnicos, enfim, faz da agricultura, apesar de sua imensa pulverização na oferta, um dos segmentos mais sujeitos ao controle social.

A renda agrícola é um tema decisivo de discussão pública e responde a critérios institucionalmente estabelecidos. Não é mais o mercado que imprime chancela social ao produto pelo mecanismo dos preços: esta função de validação de seu trabalho foi transferida gradualmente para o Estado. É o Estado o guardião da renda agrícola, que estipula seu nível e arca com as despesas a ela correspondentes. (ABRAMOVAY, 1998, p. 202).

Atualmente, nos países europeus desenvolvidos, a sustentabilidade da agricultura, bem como a sua viabilização econômica e socioambiental, tem sido implementada e regulada pelo fundo estatal constituído para esse fim. Segundo Abramovay (1998, p. 203), “a agricultura não é encarada pela sociedade e pelos próprios agricultores na qualidade de empreendimento do qual se pode esperar a obtenção de lucros, como em qualquer outra atividade comercial". Após ter optado por incentivar as unidades de produção de tipo familiar, o Estado passou a determinar institucionalmente um nível de renda para os agricultores. Uma comissão formada por representantes dos agricultores, do Estado e dos 
poderes municipais é a responsável por analisar qualquer modificação na estrutura agrária, podendo até mesmo vetar o agrupamento de pequenas explorações agrícolas que viessem a dar origem a explorações indesejavelmente grandes. Com base em sua política de estruturas, o Estado pôde estipular uma política de rendas para a agricultura e de preços agrícolas ao consumidor. Conforme demonstra Oury (apud ABRAMOVAY, 1998, p. 202) "Com esta política consegue conciliar dois objetivos básicos: garantir ao menor preço a produção de gêneros alimentares e agrícolas; e garantir um nível de vida suficiente à população agrícola, nomeadamente pelo aumento da renda individual dos que trabalham na agricultura"

A produtividade não é mais o critério exclusivo da própria excelência técnica. $\mathrm{O}$ meio ambiente, a qualidade de vida, o temor da desertificação rural tornam-se fatores a serem levados em conta na própria alocação dos fundos públicos, que marca indelevelmente a existência dos agricultores. A diversificação e a pluriatividade dos agricultores ganham um sentido que extrapola a esfera puramente econômica.

Para se ter uma idéia, na França, em 2001, os subsídios para a produção de trigo situavam-se em torno de dois mil e quinhentos francos por hectare. O preço de venda do trigo no mercado, nesse mesmo ano, correspondia a R\$208,00 por tonelada; valor que era complementado pelo governo, que destinava ao produtor o correspondente a $\mathrm{R} \$ 133,00$ por tonelada, fazendo com que o agricultor alcançasse $\mathrm{R} \$ 341,00$ por tonelada, proporcionando-lhe um percentual de lucro. Não fosse o subsídio, o prejuízo seria de $8 \%$, aproximadamente. (FEDERAÇÃO DA AGRICULTURA DO PARANÁ - FAEP, 2001). Esse fato demonstra que a competitividade da produção agrícola em geral era viabilizada pelo fundo público para financiamento da produção.

A preocupação com o meio ambiente é outro elemento social incluído em decorrência da socialização dos custos da produção. Neste item, ao estabelecer a obrigatoriedade da preservação de uma determinada área de terra, o fundo de financiamento precisa estabelecer compensações. No caso francês, $o$ agricultor recebe do fundo da Comunidade Européia dois mil francos por hectare de área preservada como incentivo (FAEP, 2001). Logo, é em virtude dos subsídios que os agricultores europeus conseguem desenvolver uma agricultura multifuncional, com ênfase na integração e harmonização entre objetivos econômicos, ecológicos e sociais, tornando a agricultura sustentável.

Abramovay (1998, p. 179) observa que não se trata de característica exclusivamente européia. Nos Estados Unidos, somente o complexo militar recebe atenção governamental tão relevante quanto a agricultura. Em 1978, naquele país, nada menos que $54 \%$ da receita das unidades de produção agrícolas familiares originou-se de pagamentos governamentais, e envolvia garantias de preços, controle da oferta e estocagem.

Citamos, a seguir, como exemplo, uma relação custos de produção/preços alcançados no mercado pelos produtos milho e feijão. Escolhemos esses produtos porque, no Brasil, eles têm sido os carroschefe da produção na maioria das unidades de produção agrícolas familiares.

Conforme a estimativa de custos de produção realizada pelo Departamento de Economia Rural (DERAL) em novembro de 2005, para a safra 2005/2006, na região Oeste do Paraná, os custos com a produção de milho, modalidade convencional, levando-se em conta apenas os custos variáveis que incluem agrotóxicos; fertilizantes; sementes; operação de máquinas e equipamentos; assistência técnica, mão-de-obra temporária; despesas com manutenção de benfeitorias; pró-agro/seguro; juros; transporte externo; recepção secagem e armazenamento - eram de $\mathrm{R} \$ 1.135,97$ por hectare. Caso se confirmasse a produção estimada de 100 sacos por hectare, resultaria num custo por saco de $60 \mathrm{~kg}$ de $\mathrm{R} \$ 11,36$. Caso contabilizemos também os custos fixos, (assim como é feito por 
uma empresa capitalista),como a depreciação de máquinas e equipamentos; as benfeitorias e instalações; a sistematização e correção do solo; o seguro do capital; a mão-de-obra permanente; a remuneração do capital próprio e remuneração da terra, teríamos um custo por hectare de $\mathrm{R} \$ 1.843,04$. Assim, considerada a mesma produtividade, o custo de produção por saco chega a R\$ 18,43 (PARANÁ, 2006). Porém, uma outra pesquisa realizada em abril de 2006, em período posterior à colheita daquele produto, que foi plantado em novembro de 2005 , verificou que o valor pago pelo mercado por saco de $60 \mathrm{~kg}$ oscilava entre $\mathrm{R} \$ 10,50$ e $\mathrm{R} \$ 11,00$, e esse valor que não cobre nem mesmo o custo dos fatores variáveis. Considerando-se que o agricultor familiar necessita vender o produto imediatamente para saldar dívidas contraídas com fornecedores e bancos financiadores, sem poder, portanto, armazená-lo para aguardar melhores preços, o prejuízo é certo.

Com relação à produção de feijão preto, conforme a estimativa de custos levantados pelo mesmo Departamento de Economia Rural em agosto de 2006 para safra 2006/2007, verificou o seguinte: para produzir-se um saco de $60 \mathrm{~kg}$, levando-se em conta os mesmos custos variáveis citados em relação ao milho, tinha-se um custo de $\mathrm{R} \$ 42,71$, para uma previsão de produção de 28 sacos por hectare, média da região. Quando são incluídos os custos fixos - a exemplo do que foi feito em relação ao milho - os custos de produção do feijão saltam para $\mathrm{R} \$ 65,32$ por saco. Porém, uma pesquisa que fizemos em fevereiro de 2007, período posterior à conclusão da colheita da referida safra, verificou que o valor pago pelo mercado era de R $\$ 32.00$ por saco de $60 \mathrm{~kg}$.

Os fatos reais, acima mencionados, desencorajam qualquer pretensão, por mais ideológica que seja, de tratar a produção agrícola como uma mercadoria qualquer, e deixar a organização da sua produção ser orientada exclusivamente pelos mecanismos do mercado.

Não estamos aqui sugerindo que a agricultura familiar em sua totalidade, como segmento da produção agrícola, só conseguiu reproduzir-se graças às políticas de proteção instituídas pelo Estado. Apenas chamamos a atenção para o fato que os estudos têm demonstrado: a modernização, da forma como tem sido imposta pela indústria para a agricultura, é inviável para este segmento e só pode ser implementada se for subsidiada pela política estatal.

\section{As Estratégias Desenvolvidas pelos Agricultores}

As políticas estatais são indispensáveis para a modernização da produção agrícola em unidades familiares, mas não podemos esquecer a importância que têm as estratégias de sobrevivência que os próprios agricultores elaboram. Isso se verifica sobretudo nas sociedades em que predominaram governos autoritários, pois nelas os agricultores tiveram que abrir caminhos e inventar alternativas para reproduzirem-se social e economicamente. Os agricultores aliaram a produção para o autoconsumo e a produção para o mercado, e souberam aproveitar as possibilidades de mobilização espaciais, mesmo com um sistema de posse precária da terra, e, assim, conseguiram transmitir como patrimônio, através das gerações, um modo de vida.

A importância dos conhecimentos transmitidos foi comprovada pelas pesquisas que resultaram no livro "Agricultura Familiar: uma comparação internacional", editado em 1993. Segundo concluíram estes estudos:

Se a exploração agrícola familiar está um pouco presente em toda parte do mundo, apesar das numerosas tormentas econômicas e políticas que ela teve que enfrentar, é sem dúvida graças à sua capacidade de adaptação. Apesar de ter que se adaptar aos contextos socioeconômicos próprios das sociedades, as quais a obrigaram a realizar modificações importantes em sua forma de produzire em sua organização social. As unidades de produção que melhor souberam superar os obstáculos, sempre 
se basearam na estratégia da valorização dos recursos de que ela dispõe internamente no estabelecimento familiar e se destinam a assegurar a sobrevivência da família no presente e no futuro (LAMARCHE, 1993, p. 21).

\section{Conseqüentemente:}

As unidades de produção familiares que estão em maiores dificuldades são aquelas em que os agricultores estão desprovidos de praticamente todo o seu patrimônio sociocultural, seja porque renegaram profundamente a maior parte dos valores que os constituem, seja porque seus pais, por diversas razões, não julgaram oportuno transmitirlhes tais valores. Ao perder esse patrimônio, eles perderam também um capital de conhecimentos, por meio dos quais poderiam encontrar soluções alternativas. (LAMARCHE, 1993. p. 21).

$\mathrm{O}$ estudo concluiu, ainda, que as unidades de produção com maiores chances de sobreviver às crises que, costumeiramente abatem-se sobre a agricultura são exatamente aquelas que mantêm uma relativa independência em relação aos determinantes de mercado: estabelecimentos nos quais a família agricultora se preocupa com a reprodução do seu modo de vida e orienta suas atividades para um compartilhamento de produção para o autoconsumo com produção para o mercado. Mesmo quando essas unidades estão integradas à agroindústria capitalista com um produto especializado, frango ou suíno, por exemplo, mantêm uma produção diversificada. Assim, quando ocorre perda em uma espécie cultivada, ou mesmo quando a agroindústria à qual estiverem integradas passar por crises, podem contrabalançar o prejuízo viabilizando o empreendimento familiar.

Utilizar insumos encontrados ou produzidos na própria unidade agrícola e fazer uso dos conhecimentos herdados ou adquiridos com a prática cotidiana reduz os custos de produção. Com isso, a unidade conquista uma relativa autonomia para organizar sua atividade, para tomar suas decisões, quanto ao que plantar, quando plantar e, o mais importante, quando vender o produto excedente.

\section{Condições Impostas ao Desenvolvimento da Agricultura Familiar no Brasil}

Conforme Offe (1984) e Habermas (1983), quando o Estado assume a tarefa de gerenciamento da economia fica permeado por interesses externos. Ao invés de uma instituição autônoma devotada a valores universalistas, ele se torna uma arena para os conflitos entre os mais diversos interesses. Em condições concretas, grupos particulares entram em conflito a respeito de certas questões e o resultado desses conflitos é uma forma particular de organização e um conjunto determinado de políticas. Ou seja, o resultado dos conflitos determina as políticas que o Estado implementa.

A julgar o atual desenvolvimento da agricultura familiar observado nas sociedades com democracia consolidada, em contraposição à realidade verificada na sociedade brasileira, por exemplo, com regime autoritário até bem pouco tempo, podemos argumentar que a agricultura familiar, para se desenvolver em condições modernizadas, depende de um ambiente democrático com uma esfera pública consolidada. E, se concordarmos que as decisões, em tese, são tomadas em função das relações de poder vigentes nessa sociedade, poderemos, ainda, sugerir que a falta de representatividade política constitui-se no fator decisivo para explicar por que em países subdesenvolvidos de capitalismo autoritário a pequena produção agrícola não foi incluída nos planos do poder público. Como se sabe, nessas sociedades, a reprodução social da pequena produção familiar ficou condicionada às estratégias elaboradas pelos próprios agricultores, restando àqueles que quisessem ter acesso a insumos e tecnologias modernizadas, a condição, de ter que articular-se aos setores capitalistas tradicionais: agroindústrias, cooperativas e comerciantes.

No Brasil, até o início da última década do século $\mathrm{XX}$, enquanto o país era governado de forma autoritária, o pequeno agricultor dependia do comerciante local e, principalmente, das estratégias que elaborava, para conseguir cultivar 
suas lavouras. O comerciante lhe cedia sementes e insumos agrícolas em troca do comprometimento da futura produção. Se necessitasse de empréstimos, a única alternativa era recorrer ao usurário, que, na maioria das vezes, era o próprio comerciante. Isso acontecia porque o Estado brasileiro fez a opção de apoiar o modelo de produção praticado nas grandes propriedades monocultoras voltada à exportação.

Como o pequeno não consegue acesso ao sistema financeiro, estruturado segundo os moldes nacionalmente dominantes, seja por não disporem da propriedade da terra, seja por não despertarem nos bancos a confiança que desfrutam os grandes proprietários. O comerciante financia uma grande quantidade de insumos, para supostas plantações, e a revende para os pequenos produtores, fiado, com juros altíssimos. (ABRAMOVAY, 1998, p. 123).

No período da internalização do processo de industrialização, o crédito representou apenas uma forma de transferência de recursos para beneficiar o desenvolvimento da indústria para a agricultura. A liberação dos recursos estava vinculada à aquisição de máquinas e insumos agrícolas industrializados. Ainda assim, foram as grandes propriedades que receberam todo o estímulo expresso na política agrícola, que procurou modernizá-la e assegurar a sua reprodução, como modelo de produção agrícola.

O sociólogo José de Souza Martins (1975), ao estudar as relações entre a industrialização e a constituição da economia nacional e a sua repercussão na sociedade e na economia rural, observou que a inserção do meio rural na economia e na sociedade foi pensada a partir dos valores urbanos.

Tanto os técnicos e os órgãos de opinião, quanto os grupos políticos partem de suposto fundamentalmente igual para avaliar as condições sociais, econômicas e culturais do homem rural. Supõem a sociedade agrária como mundo à parte, esdrúxulo, no ‘todo' que é definido pela perspectiva urbana. Pressupõem uma unilateral dependência do rural em relação ao urbano que se moderniza e neste se integra apenas na medida em que consome os produtos e os estilos de vida da sociedade urbana. A sociedade rural deve integrar a totalidade do sistema social como compradora e consumidora de mercadorias e como mercado. O diagnóstico no caso, mecanicamente estabelecido, é o de que se está diante de um regime de baixa produtividade que se modificaria pela injeção de crédito oficial e pela 'modernização' dos empreendimentos agrários (MARTINS, 1975).

Conforme constatou Martins (1975), o trabalho dos técnicos ligados à modernização -agrônomos, extensionistas, assistentes sociais rurais - visavam, mais, a tornar os agricultores consumidores de produtos da indústria urbana do que viabilizar a sua produção. Se a preocupação fosse com a modernização da produção, teriam desenvolvido mecanismos de política direcionados para o desenvolvimento de máquinas e equipamentos adaptados às unidades de produção familiares, ademais, teriam tornado acessível a sua aquisição pelos agricultores.

Conforme Wanderley (1999), o cultivo de produtos comercializáveis somados ao autoconsumo sempre foi uma orientação comum dos pequenos agricultores. A experiência do envolvimento nessa dupla face da atividade produtiva gerou um saber específico que pôde ser transmitido através das gerações sucessivas e serviu de base para o enfrentamento da precariedade e da instabilidade. Esse saber fundamenta a complementação e a articulação entre a atividademercantile a subsistência efetuada sobre a base de uma divisão do trabalho interno da família. A existência de uma fronteira agrícola no interior do país foi outra condição que permitiu aos pequenos agricultores garantirem a autonomia do seu modo de vida, especialmente pelo fato da existência de terras livres, acessíveis por meio do sistema de posses.

A integração ao mercado e a garantia do autoconsumo é fundamental para a constituição do chamado patrimônio sociocultural da agricultura familiar brasileira. 
A partir da promulgação da constituição de 1988, com a conseqüente redemocratização do País, possibilitou a entrada em cena de movimentos sociais como o Movimento dos Trabalhadores Sem Terra (MST) e os sindicatos de trabalhadores rurais, e, com isso, os pequenos agricultores familiares puderam incluir suas reivindicações na pauta de discussões que decidem o modelo de desenvolvimento a ser adotado pelo Brasil. Até à década de 1990, não existia nenhum tipo de política específica para a pequena agricultura de modelo familiar. Só a partir de 1994, com o Programa de Valorização da Pequena Produção Rural (Provap), é que a agricultura familiar passou a fazer parte, ainda timidamente, dos programas doEstado brasileiropara a agricultura, como setor diferenciado. Porém esse programa obteve resultados pouco expressivos, em razão das dificuldades que os agricultores familiares encontravam para se enquadrar nas exigências do sistema financeiro. Com isso, o volume de recurso que efetivamente foram aplicados no setor no ano de 1995 foi de apenas 93 milhões de reais, com 32 mil contratos formulados entre o sistema financeiro e os pequenos proprietários rurais (DA SILVA, 1999).

Contudo, a partir de 1996, com implementação do Programa Nacional de Fortalecimento da Agricultura Familiar (Pronaf), que abrange crédito rural para custeio e investimento, infra-estrutura, serviços e capacitação, os investimentos da política agrícola passaram a beneficiar verdadeiramente a agricultura familiar. Desde então, os recursos para a agricultura familiar têm aumentado progressivamente, saindo dos aproximadamente 650 milhões de reais, que resultaram em 332,828 contratos em 1996, para 4,5 bilhões de reais, com 1 milhão e 400 mil contratos na safra 2003/2004, para 7 bilhões de reais e 1 milhão e 800 mil contratos na safra 2004/2005.

A disponibilização de crédito com aval do poder público se fez acompanhar da queda dos juros para a agricultura familiar. Em 1995, os juros praticados pelo sistema financeiro, que eram de $16 \%$ ao ano, caíram para 12\% em 1996, e declinaram progressivamente até estacionar em $4 \%$ ao ano, em média. Em casos especiais (como para agricultores com renda bruta de até 2 mil reais anuais), os juros podem chegar a $1 \%$, mas o empréstimo, nesse caso, limitado a mil reais (BANCO DO BRASIL, 2004).

Embora a agricultura familiar tenha passado a fazer parte dos planos do Estado brasileiro, inversamente ao que se verifica nos países europeus desenvolvidos, aqui ela não é prioridade. Conforme dados do INSTITUTO NACIONAL DE COLONIZAÇÃO E REFORMA AGRÁRIA - INCRA (2006), em 2005, o número total de estabelecimentos rurais no Brasil era de 4.859.864. Excluindo-se as propriedades pertencentes ao poder público, temos a seguinte distribuição: 4.139.369 são de estabelecimentos rurais familiares e 554.501 de estabelecimentos rurais patronais ou grandes propriedades. Essa opção preferencial pelas grandes propriedades se manifesta na hora de destinar recursos para financiar a produção agrícola. Conforme dados do próprio Ministério da Agricultura, na safra 2004-2005, dos 32 bilhões de reais destinados ao financiamento da produção agrícola, apenas 7 bilhões de reais, ou 21,8\%, foram destinados a financiar a produção agrícola praticada em estabelecimentos familiares, enquanto os grandes proprietários ficaram com 27 bilhões de reais ou $78.2 \%$ do total dos recursos. Essa disparidade se acentua ainda mais para a safra 2006-2007, quando, dos 60 bilhões de reais destinados ao setor agrícola, apenas 10 bilhões de reais, ou seja, 16,7\% foram destinados aos estabelecimentos agrícolas familiares, sendo os grandes estabelecimentos contemplados com 50 bilhões de reais, ou $83,3 \%$ do total dos recursos (BRASIL, 2006). A explicação para tal atitude do Estado brasileiro pode ser encontrada na tese da dependência estrutural. $\mathrm{Na}$ maximização do rendimento da política pública, o Estado oferece serviços, infra-estrutura e mesmo recursos financeiros ao setor privado, com vistas a elevar a capacidade de lucratividade deste, na esperança de que parte desses lucros privados retorne aos cofres públicos na forma de impostos e contribuições. Como os retornos não são suficientes 
para atender às demandas por recursos de todos os setores da produção, o Estado optou por investir, preferencialmente, naqueles setores que apresentam maior rentabilidade econômica, em detrimento daqueles que apresentam tendência a oferecer prioritariamente rendimentos sociais. Com isso, deixa os setores deficitários, do ponto de vista de reembolso das políticas públicas, à mercê do mercado. Se for isso, então a crítica às políticas de subsídio implementadas pelos governos dos países economicamente desenvolvidos pode representar um desvio do foco real das atenções, por impedir que os agricultores familiares desvendem as verdadeiras intenções dos governantes.

Se for verdade o que prevê a democracia liberal, pode acontecer que, em uma sociedade democrática, cada grupo social, ou mesmo cada setor produtivo, alcance resultados proporcionais à sua representatividade, ou capacidade de influenciar nas decisões daqueles que são responsáveis por organizar a sociedade, assim, o segmento agricultura familiar está sub-representado politicamente. Esse fato ocorre por inexistir uma legislação que defina a atividade agricultura familiar, principalmente, em termos de extensão da área da propriedade agrícola, e isso permite que um grande contingente de produtores ainda sejam enquadrados como empregadores rurais, mesmo não tendo área suficiente para empregar todos os membros da família. Também pode ocorrer que esses agricultores sejam enquadrados como trabalhadores rurais, mesmo sendo proprietários de uma pequena área de terra*. Lembremos que, conforme o conceito, "agricultura familiar é aquela onde a família, ao mesmo tempo em que é proprietária dos meios de produção, assume o trabalho no estabelecimento produtivo" (WANDERLEY, 1999, p. 25). Não é necessariamente pequena, mas precisa unir na mesma unidade produtiva: família-produção- trabalho.

Ao que parece, ainda hoje, o Estado brasileiro não dispõe de um programa que vise a produzir máquinas e implementos agrícolas voltados ao segmento agricultura familiar, não contando, nem mesmo, com uma política de concessão de crédito para aquisição desses equipamentos. De acordo com Silvio Crestana, na época diretor-presidente da Empresa Brasileira de Pesquisa Agropecuária (Embrapa):

O governo está agora (2005) montando uma política para alavancar o setor de implementos e máquinas agrícolas para o segmento familiar. Hoje há financiamentos do BNDES para a compra de máquinas, mas voltadas para a média e grande propriedade e isso tem viabilizado a modernização do parque mecânico brasileiro. Mas na pequena isso não existe. Os Ministérios da Agricultura, da Ciência e Tecnologia, do Desenvolvimento Agrário e a Embrapa estão fechando um projeto para garantir o acesso do agricultor familiar a máquinas adequadas para o porte da sua propriedade. E esse projeto virá em parceria com a iniciativa privada que irá fabricar esses equipamentos em escala para baratear o custo. Então, o projeto vai incluir o crédito, a tecnologia, a necessidade do pequeno produtor e a indústria para produzir (EM QUESTÃO, 2005). São informações que corroboram a tese defendida por Kautsky e outros marxistas, que as máquinas e os equipamentos desenvolvidos para modernizar a agricultura não são compatíveis com a realidade da pequena produção. "A desvinculação da racionalidade técnica e da racionalidade do capital indica os componentes ideológicos orientadores da ação inovadora"(MARTINS, 1975, p. 27).Ainda está em curso a ideologia da urbanização, pela negação do mundo rural. A valorização do "moderno" contra o "tradicional", impõe a modernização, sem se preocupar em saber se as transformações técnicas

Sobre esse assunto, cabe ressaltar que, no dia 24 de julho de 2006, foi sancionada a lei que regulamenta a profissão agricultor familiar. Resta-nos esperar a aplicação da lei para ver se o problema aqui apontado é de fato o responsável pelo descaso com a agricultura familiar. 
são viáveis economicamente. Daí resultam as concepções de que o agricultor é ignorante, quando resiste à adoção de equipamentos, máquinas, insumos e novas tecnologias, comercializados pela indústria capitalista urbana. Mais ainda, aquilo que não é trocado no mercado não tem valor, não é contabilizado como rendimento da propriedade. Por isso, a produção para o consumo da família não entra nos cálculos, é desprezada ou ignorada como se não existisse, levando a conclusões equivocadas, como aquelas que apontam um baixo nível de rendimento da propriedade familiar.

\section{Algumas Considerações Finais}

Os estudos que consultamos para embasar este trabalho contestam a percepção evolucionista das transformações daagriculturamodernaedemonstram que os agricultores mais envolvidos e dependentes do mercado são precisamente os mais fragilizados pela própria crise do mercado. Demonstram, ainda, que o recurso ao autoconsumo e à reutilização de produtos e insumos da própria unidade de produção, longe de significar um atraso tecnológico, possibilita a redução do endividamento financeiro, melhorando a capacidade de enfrentamento das condições adversas para sobreviver às crises costumeiras do mercado.

Fica evidente que a atividade agrícola praticada em unidades familiares, quando tem a sua modernização empreendida nas condições impostas pela indústria para a agricultura, não dá lucros para os agricultores. As tecnologias, as máquinas e os equipamentos desenvolvidos para a agricultura se modernizar não são compatíveis com a realidade de uma pequena unidade de produção. Também os detentores do poder estatal nos países europeus desenvolvidos chegaram à conclusão que a modernização da agricultura familiar e conseqüente transformação permanente dependem da intervenção do Estado.

A instituição de um patamar tecnológico com a garantia de um nível satisfatório de renda para a família agricultora, nos países de capitalismo avançado, tem sido conseguida graças à intervenção do Estado. Graças aos subsídios. Agora, esse modelo tem sofrido grandes pressões por parte dos representantes políticos dos países em desenvolvimento, do próprio governo brasileiro, que querem vê-lo desativado.

É a evidência de que as concepções e os diagnósticos parciais e ideológicos, identificados por José de Souza Martins (1975), têm conduzido, propositadamente ou ingenuamente, a programas de extensão rural e políticas agrícolas equivocadas, que, ao invés de melhorar as condições de vida do agricultor, acabam contribuindo para a sua extinção.

Uma coisa, porém, é certa, a interação da unidade de produção agrícola familiar com o mercado capitalista não pode anular suas especificidades, preparando a metamorfose do agricultor familiar em empresário rural, como querem alguns tecnocratas a serviço do capital industrial. É preciso reconhecer o agricultor familiar como agente social importante da produção agrícola e legitimá-lo do ponto de vista social e político.

Mais que isso, as conclusões a que chegaram as análises relacionadas às possibilidades da agricultura familiar na sociedade contemporânea, reconhecendo a eficiência da prática de compartilhamento de produção para o autoconsumo e produção para o mercado, dão novo alento à discussão do tema. Mantém-se, assim, atual o debate sobre a possibilidade de haver uma mesclagem de conhecimentos chamados tradicionais, aqueles que foram transmitidos de geração a geração ou adquiridos com a prática, com os conhecimentos técnicos e científicos, ditos modernos, vendidos pela indústria de insumos e equipamentos para a agricultura.

Nesse modelo, a agricultura familiar pode obter uma relativa autonomia em relação aos condicionantes de mercado, recorrendo minimamente ao sistema financeiro para emprestar 
dinheiro para realizar a produção. Nele, o agricultor conduz as atividades na sua unidade de produção com vistas a reproduzir um modo de vida. Recorre àquele que, segundo Forman (apud ABRAMOVAY, 1998, p. 111), tem sido ao longo dos tempos "o princípio básico organizador da unidade de produção agrícola familiar: a maximização da segurança e a minimização do risco."

Já que o agricultor familiar não pode interferir na definição do preço de venda do produto agrícola para the assegurar uma margem de lucro, ele precisa voltar sua atenção para a diminuição dos custos da produção. Isso está ao seu alcance. E é esse o ponto central da questão que precisa ser atacado atualmente. Uma retomada do controle das ações que pode ocorrer à medida que o agricultor proceder à substituição dos insumos industrializados pela utilização de adubação natural, produção de sementes, produção de todos aqueles produtos alimentares para o consumo da família que podem ser produzidos na unidade de produção familiar. Um modelo de produção onde o cuidado com o meio ambiente pode assumir um papel importante.

A condução do processo produtivo precisa preocupar-se, também, com a qualidade da produção e não apenas com a quantidade. Isso porque, conforme temos visto ocorrer freqüentemente, principalmente naquelas unidades familiares que mergulharam a fundo na modernização e especialização na produção de um único produto, o agricultor tem colhido grandes quantidades e no fim contabilizado prejuízos.

\section{Referências}

ABRAMOVAY, R. Paradigmas do capitalismo agrário em questão. Campinas: UNICAMP, 1998.

BANCO DO BRASIL. Manual de politica rural. n. 4, out./nov./dez. 2004.

BRASIL. Ministério da Agricultura. Plano agrícola e pecuária 2006/2007. Brasília, 2006. Disponível em: $<$ www.ma.gov.br>. Acesso em: 16 jun. 2005.
DA SILVA, E. R. Pronaf: uma avaliação das ações realizadas no período 1995 - 1998. Brasília: IPEA, 1999.

EM QUESTÃO. Boletim informativo eletrônico do Partido dos Trabalhadores. Disponível em: <www. pt.org.br>. Acesso em: 26 abr. 2005.

FEDERAÇÃO DA AGRICULTURA DO PARANÁ FAEP. Boletim Informativo, Curitiba, n.676, jun. 2001.

HABERMAS, J. Para a reconstrução do materialismo histórico. São Paulo: Brasiliense, 1983.

Técnica e ciência enquanto "ideologia". São Paulo: Victor Civita, 1975. (Os Pensadores).

Teoria de la acción comunicativa: critica de la razón funcionalista. Madri: Cadedra, 1989. t.2.

INSTITUTO NACIONAL DE COLONIZAÇÃO E REFORMA AGRÁRIA - INCRA. Atlas fundiário brasileiro. Brasília, 2006. Disponível em: <www.incra. gov.br>. Acesso em: 10 nov. 2005.

KAUTSKY, K. A questão agrária. São Paulo: Nova Cultural, 1986.

LAMARCHE, H. (Coord.). Agricultura familiar: comparação internacional. Campinas: UNICAMP, 1993. v. 1.

(Coord.). Agricultura familiar: do mito à realidade. Campinas: UNICAMP, 1998. v. 2.

LÊNIN, V. I. O desenvolvimento do capitalismo na Rússia. São Paulo: Abril, 1982.

MARTINS, J. S. Capitalismo e tradicionalismo: estudo sobre as contradições da sociedade agrária no Brasil. São Paulo: Pioneira, 1975.

MARX, K. O capital: crítica da economia política. 3. ed. Rio de Janeiro: Civilização Brasileira, 1980. v. 6.

OFFE, C. Problemas estruturais do estado capitalista. Rio de Janeiro: Tempo Brasileiro, 1984.

OLIVEIRA, F. O surgimento do antivalor. Novos Estudos Cebrap, São Paulo, n. 22, p. 8-28, out. 1988.

PARANÁ. Secretaria de Estado da Agricultura e do Abastecimento do Paraná-SEAB. Estimativas de custos. Curitiba, 2006. Disponível em: <www.seab.pr.gov.br>. Acesso em: 30 mar. 2006.

PRZEWORSKY, A. Estado e economia no capitalismo. Rio de Janeiro: Relume-Dumará, 1995.

WANDERLEY, M. N. B. Raizes históricas do campesinato brasileiro. In: TEDESCO, J. C. (Org.). Agricultura familiar: realidades e perspectivas. Passo Fundo: EDIUPF, 1999. p. 23-56. 